\title{
Mechanism of pH Dependent Decomposition of Monoalkylamine Diazeniumdiolates to Form HNO and NO, Deduced from the Model Compound Methylamine Diazeniumdiolate, Density Functional Theory and CBS-QB3 Calculations
}

\author{
Andrew S. Dutton ${ }^{1}$, Christopher P. Suhrada ${ }^{1}$, Katrina M. Miranda ${ }^{2}$, David A. Wink ${ }^{3}$, Jon M. \\ Fukuto $^{4}$, and K. N. Houk ${ }^{1, *}$ \\ ${ }^{1}$ Department of Chemistry and Biochemistry, University of California, Los Angeles, CA 90095 \\ ${ }^{2}$ Department of Chemistry, University of Arizona, Tucson, AZ 85721 \\ ${ }^{3}$ Radiation Biology Branch, National Cancer Institute, Bethesda, MD 20892 \\ ${ }^{4}$ Department of Molecular and Medical Pharmacology, Center for the Health Sciences, University \\ of California, Los Angeles, CA 90095
}

\begin{abstract}
Isopropylamine diazeniumdiolate, IPA/NO, the product of the reaction of isopropylamine and nitric oxide, $\mathrm{NO}$, decomposes in a $\mathrm{pH}$ dependent manner to afford nitroxyl, $\mathrm{HNO}$, in the $\mathrm{pH}$ range of 13 to above 5 and NO below $\mathrm{pH}$ 7. Theoretical studies using B3LYP/6-311+G(d) density functional theory, the PCM and CPCM solvation models and the high accuracy CBS-QB3 method on the simplified model compound, methylamine diazeniumdiolate, predict a mechanism involving $\mathrm{HNO}$ production via decomposition of the unstable tautomer $\mathrm{MeNN}^{+}\left(\mathrm{O}^{-}\right) \mathrm{NHO}^{-}$. The production of $\mathrm{NO}$ at lower $\mathrm{pH}$ is predicted to result from fragmentation of the amide/ $\mathrm{NO}$ adduct upon protonation of the amine nitrogen.
\end{abstract}

\section{Introduction}

\begin{abstract}
Amine NONOates, also known as amine diazeniumdiolates, possess the general structure of $\mathrm{RR}^{\prime} \mathrm{N}[\mathrm{NONO}]^{-}$and are formed from the reaction of a suitable amine with nitric oxide, NO. ${ }^{1,2}$ Dialkylamine NONOates have been used extensively in chemistry and biology as sources of $\mathrm{NO}$, as these compounds decompose in a predictable $\mathrm{pH}$-dependent manner to produce two molecules of $\mathrm{NO}^{3}{ }^{3} \mathrm{NO}$ has been demonstrated to be a signaling molecule of vital importance for immunology, neurobiology and cardiology. ${ }^{4}$ The mechanistic details by which dialkylamine NONOates decompose, via thermal or photochemical processes, has been of interest both experimentally and theoretically. ${ }^{5,6}$ We provided a theoretical prediction of the mechanism in which protonation of the most basic position, $\mathrm{O}(2)$, gives an unreactive isomer while protonation of the much less basic amino nitrogen leads to rapid dissociation yielding the neutral amine and two molecules of NO. ${ }^{7}$
\end{abstract}

Nitroxyl, HNO, is the protonated one-electron reduction product of NO. HNO is a reactive molecule that readily dimerizes with a second order rate constant ${ }^{8}$ of $8 \times 10^{6} \mathrm{M}^{-1} \mathrm{~s}^{-1}$ and is

houk@chem.ucla.edu.

SUPPORTING INFORMATION

Cartesian coordinates for all optimized structures; complete references 18, 20, and 25. 
proposed to react with oxygen with a rate constant of $8 \times 10^{3} \mathrm{M}^{-1} \mathrm{~s}^{-1}$ as measured by Liochev et al. ${ }^{9}$ or $3 \times 10^{3} \mathrm{M}^{-1} \mathrm{~s}^{-1}$ determined by Miranda et al. ${ }^{10}$ The ground state of HNO is a singlet. The tautomer $\mathrm{NOH}$, which is a ground state triplet, is $25.7 \mathrm{kcal} / \mathrm{mol}$ higher in energy in the gas phase, or $26.4 \mathrm{kcal} / \mathrm{mol}$ in water. ${ }^{11} \mathrm{HNO}$ is a weak acid, possessing a pKa of $\sim 11.4$, and deprotonation to the triplet ground state anion is spin forbidden, ${ }^{12}$ which provides a significant barrier to proton transfer. In water, deprotonation of HNO has been determined by Lymar and co-workers to be base-catalyzed, with an unusually low rate constant of $5.5 \times 10^{4} \mathrm{M}^{-1} \mathrm{~s}^{-1.13}$ The understanding of the biological significance of HNO is still in its infancy, but this small molecule has been implicated in physiological effects that are distinct from those of $\mathrm{NO}^{14}$

The inorganic salt sodium trioxodinitrate, or Angeli's salt, is also a diazeniumdiolate, but decomposition at neural $\mathrm{pH}$ produces HNO rather than NO. Angeli's salt has been widely used to study the biological effects of HNO. ${ }^{14}$ The mechanism for decomposition of Angeli's salt has been debated in the literature since Angeli first published ${ }^{15 a}$ in the late 19th century that the end products were nitrite, $\mathrm{NO}_{2}{ }^{-}$, and nitrous oxide, $\mathrm{N}_{2} \mathrm{O}$, in the $\mathrm{pH}$ range of 10 to 3 , while $\mathrm{NO}$ was the only nitrogen-containing product at or below $\mathrm{pH} 3 .{ }^{15}$ The mechanism of $\mathrm{HNO}$ formation is commonly accepted to involve protonation of $\mathrm{N}_{2} \mathrm{O}_{3}{ }^{2-}$ followed by tautomerization and heterolytic cleavage of the N-N bond. ${ }^{15 \mathrm{c}}$ The mechanism for NO production has been less clear. We recently reported a detailed theoretical study that supports the experimental mechanism for HNO production and suggests that NO results from double protonation of an oxygen of the nitro group. ${ }^{11}$ The theoretical kinetic parameters from our mechanism ${ }^{11}$ fit well with the experimental data ${ }^{15 c}$ that describes the pH-dependent decomposition. Despite the utility of Angeli's salt in the study of the chemistry and biology of HNO, experimentalists are limited by the properties of this nonfunctionizable salt. In contrast, amine based NONOates offer the necessary variety to investigate the effects of NO production in a complex cellular environment. Additionally, there have been recent suggestions that $\mathrm{NO}_{2}{ }^{-}$, a by-product of Angeli's salt decomposition, may play a signaling role in the cardiovascular system through conversion to NO by red blood cells. ${ }^{16}$ Thus, it is important to expand the list of compounds that can be used for the production of HNO in chemical and biological systems. The commonly used amine based NONOates are synthesized from secondary or polyamines. ${ }^{17}$ In contrast to these NO donors, decomposition in neutral solution of the amine NONOate produced with isopropylamine (IPA/NO), results in $\mathrm{HNO}$, while NO forms only at lower $\mathrm{pHs}$, in similarity to Angeli's salt. ${ }^{18 \mathrm{a}}$ Here we discuss the $\mathrm{pH}$-dependent mechanism for the decomposition of monoalkylamine NONOates, based upon quantum mechanical calculations.

\section{Methods}

All structures were initially optimized using the $\mathrm{B} 3 \mathrm{LYP}^{19}$ density functional method with a $6-311+\mathrm{G}(\mathrm{d})$ basis set implemented in the Gaussian 98 program. ${ }^{20}$ Aqueous solvation energies were calculated as single points on the B3LYP/6-311+G(d) gas phase optimized geometries using a 6-311+G(d) basis set in the polarizable continuum model, PCM, and the conductor-like polarizable continuum model, CPCM, implemented in Gaussian 98.21,22 The CPCM model has been demonstrated to provide improved aqueous solvation energies over the PCM model for a limited test set. ${ }^{23}$ Structures important to the decomposition mechanism were then computed with the more accurate CBS-QB3 extrapolative method, a series of calculations that generally give average errors of $\pm 1 \mathrm{kcal} / \mathrm{mol}$ compared to experimentally measured data for the G3 data set. ${ }^{24}$ Free energies are given for $298 \mathrm{~K}$. The aqueous solvation energies were applied to the B3LYP/6-311+G(d) and CBS-QB3 optimized gas phase energies. Key structures to the decomposition mechanism were optimized in water using the PCM model and the B3LYP/6-311+G(d) method mentioned above to better simulate the experimental aqueous environment on the mechanism; Gaussian 
03 was used for these claculations. ${ }^{25}$ All values reported in the text are at the CBS-QB3 level of theory including aqueous solvation unless otherwise noted. Absolute $\mathrm{pK}_{\mathrm{a}}$ values were computed utilizing the method developed by Riveros and co-workers and B3LYP/ 6-311+G(d) energies with CPCM aqueous solvation energies. ${ }^{26}$ Relative $\mathrm{pK}_{\mathrm{a}}$ values were predicted using the relationship between $\Delta \Delta \mathrm{G}_{\mathrm{aq}}$ and $\mathrm{pK}_{\mathrm{a}}, \Delta \Delta \mathrm{G}=1.36\left(\Delta \mathrm{pK}_{\mathrm{a}}\right)$ at $25^{\circ} \mathrm{C}$. The most basic computed $\mathrm{pK}_{\mathrm{a}}$ was set equal to the experimentally measured $\mathrm{pK}_{\mathrm{a}}$ value of $4.5 .^{25}$ These $\mathrm{pK}_{\mathrm{a}}$ values are expected to have an error of $\pm 2 \mathrm{pK}_{\mathrm{a}}$ unit.

\section{Results and Discussion}

\section{Primary amine NONOate structures}

Figure 1 shows (a) the electrostatic potential surface of the anion and the computed geometries of (b) IPA/NO and (c) the model compound used, methylamine NONOate or $\mathrm{MA} / \mathrm{NO}$, with the atom labeling scheme used throughout this article. There is great similarity between IPA/NO and the simplified model compound, MA/NO. The only discrepancy is the $0.01 \AA$ difference in bond length between the substituent and N(1). The computed structures indicate that the $[\mathrm{NONO}]^{-}$functional group is approximately planar with a dihedral angle of $178^{\circ}$ for both IPA/NO and model compound, which is similar to those found for the computed structures of dimethylamine NONOate, and Angeli's salt, $-178^{\circ}$ and $0.0^{\circ}$ respectively..$^{7,11}$ The computed structure of Angeli's salt ${ }^{11}$ is in good agreement with the crystal structure. ${ }^{27}$

\section{Primary amine NONOate synthesis}

The synthesis of amine NONOates, which involves reacting an amine in a nonpolar solvent under high pressures of NO, was developed by Drago and co-workers and later refined by Keefer and co-workers. ${ }^{2,3,17}$ During the process, the product is formed as an insoluble salt that precipitates from solution. According to B3LYP/6-311+G(d), the reaction of methylamine with $\mathrm{NO}$ to form MA/NO in its most stable neutral form is overall exothermic, but endergonic (Figure 2, equation 1). It is known that the amine NONOates are not thermodynamically stable; their preparation relies on a high pressure of $\mathrm{NO}$ and the precipitation of the NONOate from solution as an alkylammonium salt. One presumes that, similar to the dialkylamine NONOates, the reaction may proceed either via stepwise addition of $\mathrm{NO}$ or through the dimerization of $\mathrm{NO}\left(\Delta \mathrm{H}=-2 \mathrm{kcal} / \mathrm{mol} \text { for } 2 \mathrm{NO} \rightarrow(\mathrm{NO})_{2}\right)^{28}$ followed by nucleophilic attack of the amine on the NO dimer.

Equation 2 shows that the $\mathrm{E}$ isomer is computed to be $4.4 \mathrm{kcal} / \mathrm{mol}$ more stable than the $\mathrm{Z}$ isomer in the gas phase $(3.1 \mathrm{kcal} / \mathrm{mol}$ in water according to PCM (B3LYP/6-311+G(d))). The preference for the $\mathrm{E}$ isomer arises from the internal $\mathrm{H}$-bond between $\mathrm{O}(2)$ and $\mathrm{HN}(1)$, which is consistent with the reported E-preference in the simplest amine diazeniumdiolate, $\mathrm{H}_{2} \mathrm{~N}[\mathrm{NONO}]^{-}$, compared to the slight Z-preference in dimethylamine NONOate, which cannot form such a hydrogen bond. ${ }^{7}$ Rotational isomerization from $\mathrm{E}$ to $\mathrm{Z}$ has a relatively large barrier of $37.4 \mathrm{kcal} / \mathrm{mol}$ in the gas phase according to B3LYP/6-311+G(d), comparable to the rotation barrier in the parent amine NONOate $\left.\mathrm{H}_{2} \mathrm{~N}^{\mathrm{NONO}}\right]^{-}, 24.2 \mathrm{kcal} / \mathrm{mol}$, computed previously. ${ }^{7}$ Interconversion of the $\mathrm{E}$ and $\mathrm{Z}$ isomers could also be achieved by inversion at $\mathrm{N}(3)$, but attempts to determine the barrier to inversion indicate that it is much higher in energy than the rotational barrier. Inversion resulted in dissociation of the $[\mathrm{NONO}]^{-}$functional group. The large rotational barrier and the infeasibility of an $\mathrm{N}(3)$ inversion process imply that, once formed, the $\mathrm{E}$ and $\mathrm{Z}$ isomers will not readily interconvert thermally. E/Z isomerization via dissociation-recombination or via an acid- or basecatalyzed process may, however, be more facile. 


\section{Primary amine NONOate decomposition to HNO}

The properties of IPA/NO are similar to those of the dialkylamine NONOates and Angeli's salt, which are stable as solids and in strongly alkaline solutions. At high $\mathrm{pH}$, the NONO group is fully deprotonated; thus dialkylamine NONOates possess a single negative charge while Angeli's salt exists as a dianion, $\mathrm{N}_{2} \mathrm{O}_{3}{ }^{2-}$. We explored whether the amine nitrogen of $\mathrm{MA} / \mathrm{NO}$ is likely to deprotonate at high $\mathrm{pH}$ in analogy to the substituent oxygen of Angeli's salt. The relative energetics of such dibasic isomers of MA/NO are presented in Figure 3.

Figure 3 indicates that the $\mathrm{Z}$ isomers of $\mathrm{MA} / \mathrm{NO}$ deprotonated at the amine nitrogen are lower in energy than the E isomers, as computed by the B3LYP/6-311+G(d) level. The relative stability of the $\mathrm{Z}$ isomers, 1 and $1 \mathrm{a}$, varies slightly in the gas phase and in water. However, these dianions are very unstable. The $\mathrm{pK}_{\mathrm{a}}$ predicted for the dibasic isomers, using the method of Pliego and Riveros ${ }^{26}$, was determined to be approximately 29. These species should consequently have no relevance to the aqueous chemistry of MA/NO.

Decomposition of IPA/NO to HNO has been observed in the $\mathrm{pH}$ range of 13 to 5 , where the monoanion is dominant. ${ }^{18}$ The relative energetics of all plausible monobasic isomers of $\mathrm{MA} / \mathrm{NO}$ are presented in Figure 4.

The lowest energy gas phase optimized structure, $\mathbf{3}$, is an (E)-NONOate possessing an internal H-bond. In water, conformers 4, 4a and tautomers 5, 6 and $\mathbf{6 a}$ are within $3.5 \mathrm{kcal} /$ mol of 3 at the B3LYP/6-311+G(d) level using the PCM model. CPCM predicts that conformers $3, \mathbf{4}$ and $\mathbf{4 a}$ will dominate the aqueous equilibrium with conformer $\mathbf{4}$ favored by $3.1 \mathrm{kcal} / \mathrm{mol}$. The differences between the solvation methods are within the error of these continuum based models; these results predict species $3, \mathbf{4}, \mathbf{4 a}, \mathbf{5}, \mathbf{6}$ and $\mathbf{6 a}$ to be present in aqueous solutions, with $\mathbf{3}, \mathbf{4}$ and $\mathbf{4 a}$ present in greatest concentration. There is little preference for the position of the methyl group for the (Z)-NONOates as seen by comparing structures 4 to $4 \mathbf{a}, 6$ to $\mathbf{6 a}$, and $\mathbf{8}$ to $8 \mathbf{a}$. For the E isomers, a strong H-bond can result in significant stabilization of one isomer: compare $\mathbf{3}$ to $\mathbf{3 a}$, and $\mathbf{5}$ to $\mathbf{5 a}$. When $\mathrm{N}(3)$ of the (Z)NONOate is protonated, $\mathbf{1 0}$ and 10a, optimization gives the same H-bonded complex of $\mathrm{HNO}$ and the deprotonated nitrosamine, $\mathbf{1 1 .}$

The low energy isomers of each pair in Figure 4 were further computed with the more accurate CBS-QB3 method. The higher energy isomers of species 7, 8 and the high energy isomers of each pair in Figure 4 are excluded from further analysis. The relative energies for the CBS-QB3 computed structures are shown in Figure 5.

As with the B3LYP/6-311+G(d) level, 3 is the lowest energy conformer in the gas phase, although 5 and $\mathbf{6}$ were computed to be quite close in energy. When aqueous solvation was included, the PCM method put $\mathbf{6}$ as slightly lower in energy than $\mathbf{3}$, which is the opposite of the order in water determined by the B3LYP/6-311+G(d) level. The CPCM model predicted that $\mathbf{4}$ is the most stable species in water at both theory levels.

That species 10 again optimized to $\mathrm{HNO}$ and the deprotonated nitrosamine molecular complex, 11, suggesting that $\mathrm{HNO}$ is produced as a result of protonation at $\mathrm{N}(3)$. The other such isomer, 9, optimized to a stable species that is predicted to be $18.3 \mathrm{kcal} / \mathrm{mol}$ higher in energy than tautomer 3 in the gas phase and approximately $12 \mathrm{kcal} / \mathrm{mol}$ higher than the ground state species in water. Heterolytic cleavage of the $\mathrm{N}(2) \mathrm{N}(3)$ bond of 9 would also lead to $\mathrm{HNO}$ and the deprotonated nitrosoamine. In order to compare the approximate relative energies of $\mathbf{9}$ and $\mathbf{1 0}$, an optimization was performed with the $\mathrm{N}(2) \mathrm{N}(3)$ bond of species 10 constrained to $1.31 \AA$ (the optimized bond length of species 4), yielding structure $10 f$ (for fixed bond length) at the B3LYP/6-311+G(d) level (Figure 6). The B3LYP/ $6-311+G(d)$ level energies of $\mathbf{9}$, the constrained structure 10f, and the transition structure of 
the $\mathrm{NN}$ bond cleavage in structure $\mathbf{9}, \mathbf{9 t s}$, relative to the gas phase ground state isomer $\mathbf{3}$ are shown in Figure 6.

Tautomerization from 3 to $\mathbf{1 0}$, as modeled by $\mathbf{1 0 f}$, is approximately $14 \mathrm{kcal} / \mathrm{mol}$ endergonic in water. Species $\mathbf{9}$, which is $6 \mathrm{kcal} / \mathrm{mol}$ higher in energy than $\mathbf{3}$ in water, has approximately a $2 \mathrm{kcal} / \mathrm{mol}$ barrier to cleavage of the $\mathrm{N}(2) \mathrm{N}(3)$ bond. Thus, the total barrier to go from 3 to products via 9 ts is around $8 \mathrm{kcal} / \mathrm{mol}$ in water. These calculations indicate a mechanism for the decomposition of the anion through 9.

Based upon the B3LYP/6-311+G(d) and CBS-QB3 results, the PCM model for water was used to optimize 3, 4, 6,9 and 9ts. Structure 10 was also included to determine if aqueous solvation would stabilize the structure and prevent spontaneous $\mathrm{N}(2) \mathrm{N}(3)$ bond cleavage. The relative energetics are shown in Figure 7.

Optimization in water predicts that $\mathbf{4}$ is the most favorable isomer, closely followed by $\mathbf{3}$. Species 6, which was calculated to be the most stable conformer in water using the PCM method and CBS-QB3, was computed to be quite high in energy, $10.3 \mathrm{kcal} / \mathrm{mol}$ relative to species 4 , when optimized in an aqueous model environment. This is presumably caused by the fact that in the gas phase the intramolecular H-bond is more stabilizing than in the aqueous environment. Species 10, which spontaneously decomposed to $\mathbf{1 1}$ when optimized in the gas phase, formed a stable structure when optimized in the aqueous environment. It is only a shallow minimum with a barrier to decomposition via 10 ts of only $0.7 \mathrm{kcal} / \mathrm{mol}$. Isomer $\mathbf{1 0}$ provides a pathway to decomposition with a total activation free energy of 14.6 $\mathrm{kcal} / \mathrm{mol}$ from the ground state structure 4 . Species $\mathbf{9}$, which was predicted to have a small barrier to $\mathrm{N}(2) \mathrm{N}(3)$ cleavage in the gas phase, is computed to have a barrier of $1.4 \mathrm{kcal} / \mathrm{mol}$ when optimized in the PCM aqueous solvation model. The total energy for decomposition of 9 in water via transition structure 9 ts is predicted to be $13.9 \mathrm{kcal} / \mathrm{mol}$.

The relative energetics from optimization in the PCM aqueous solvation model, shown in Figure 7, confirm the preliminary results at the B3LYP/6-311+G(d) and CBS-QB3 levels in which the isomeric equilibrium in alkaline aqueous solution will be dominated by $\mathbf{3}$ and $\mathbf{4}$, with 4 slightly favored. Given the high computed barrier to rotational isomerization, this equilibrium will be skewed to $\mathbf{3}$ or $\mathbf{4}$ depending upon which is formed during the synthesis. This analysis suggests that HNO is produced by tautomerization of isomers $\mathbf{3}$ or $\mathbf{4}$ to $\mathbf{9}$ or $\mathbf{1 0}$, respectively. Thus, the mechanism of decomposition to produce $\mathrm{HNO}$ is independent of $\mathrm{pH}$, and the overall activation energy is about $15 \mathrm{kcal} / \mathrm{mol}$, through 9 ts or 10ts.

\section{Primary amine NONOate decomposition to NO}

As the solution $\mathrm{pH}$ is decreased, decomposition of IPA/NO increasingly produces NO, at the expense of HNO. ${ }^{18}$ This suggests a competition between protonation and tautomerization of isomers $\mathbf{3}$ or $\mathbf{4}$. The structures of $\mathbf{3}$ and $\mathbf{4}$ protonated at $\mathrm{N}(1), \mathrm{O}(1), \mathrm{O}(2)$, and $\mathrm{N}(3)$ were optimized, and the relative energies are shown in Figure 8.

Species 13, possessing an internal hydrogen bond, is computed to be the most stable diprotonated isomer, followed closely by the corresponding E isomer, 12. Protonation of $\mathbf{3}$ or $\mathbf{4}$ at N(1), providing 18 and 20 respectively, gave species that optimized in the gas phase to the dissociated amine and the NO dimer molecular complex, structures 19 and 21 respectively. The $\mathrm{N}_{2} \mathrm{O}_{2}$ fragment in species 19 is an excited electronic state of the trans $\mathrm{NO}$ dimer as seen previously for the dialkylamine NONOates. ${ }^{7}$

As for the monoanionic structures, the isomers in Figure 8 were further evaluated using the more accurate CBS-QB3 method, and the resulting relative energies are shown in Figure 9. 
The relative energies in Figure 9 follow the trend found in Figure 8, with $\mathbf{1 3}$ predicted to be the most stable diprotonated isomer in water and $\mathbf{1 2}$ computed to be $3 \mathrm{kcal} / \mathrm{mol}$ less stable. All other diprotonated species are found to be significantly higher in energy. Diprotonation at $\mathrm{N}(1)$ and optimization in the gas phase produces molecular complexes between the NO dimer and methylamine, $\mathbf{1 9}$ and $\mathbf{2 1}$. When separated, the free energy would become favorable with respect to $\mathbf{1 3}$. The large energy difference between $\mathbf{1 9}$ and $\mathbf{2 1}$ is caused by the formation of an electronic excited state of the trans NO dimer in $\mathbf{1 9}$ as described previously. ${ }^{7}$

To approximate the energetics required to obtain the diprotonated isomers at $\mathrm{N}(1)$, structures where the $\mathrm{N}(1) \mathrm{N}(2)$ bonds were constrained to $1.43 \AA$, the optimized bond length of species 3 , and $1.44 \AA$, the optimized bond length of species 4 , giving structures $18 \mathrm{f}$ and $20 \mathrm{f}$, respectively, are shown in Figure 10 relative to the lowest energy isomer $\mathbf{1 3}$.

The computed energies for the formation of the diprotonated structures, $\mathbf{1 8}$ and $\mathbf{2 0}$, as approximated by the constrained structures $\mathbf{1 8 f}$ and 20f, respectively, are 24.5 and $30.8 \mathrm{kcal} /$ mol, respectively, higher than that of $\mathbf{1 3}$ in the gas phase. Upon aqueous solvation the relative energies of $\mathbf{1 8 f}$ and $\mathbf{2 0 f}$ are approximately the same and about $14 \mathrm{kcal} / \mathrm{mol}$ higher in energy relative to $\mathbf{1 3}$.

The high energy isomers at both the B3LYP/6-311+G(d) and CBS-QB3 levels, 14 and 15, were excluded from further consideration. Species 12, 13, 16, 17, 18 and 20 were then further optimized in the PCM model of water to better approximate the energetics associated with the experimental aqueous solution. The relative energetics of these species optimized in water are shown in Figure 11 along with the computed $\mathrm{pK}_{\mathrm{a}}$ values, which are obtained relative to the experimental value of the $\mathrm{pK}_{\mathrm{a}}$ of $\mathbf{1 3}$.

There was less ambiguity in the order of the diprotonated isomers compared to the monoprotonated isomers at lower levels of computation, but the outcome of the PCM model analyses was quite similar. The lowest energy diprotonated species in aqueous solution calculated by the CPCM model, 13, was also predicted to be the lowest at the PCM level, with 12 only slightly higher in energy. Further, the structures that were predicted to be unstable by gas phase optimization, $\mathbf{1 8}$ and $\mathbf{2 0}$, were predicted to be stable in an aqueous model. Protonation at N(1) to produce $\mathbf{1 8}$ and $\mathbf{2 0}$ were calculated to be less energetically favorable than protonation of $\mathrm{N}(3)$ to give $\mathbf{1 6}$ or $\mathbf{1 7}$. However, the transition states for the decomposition of the $\mathrm{N}(3)$ protonated tautomers, via 16ts and 17ts to give $\mathrm{HNO}$, are higher in energy than decomposition via the $\mathrm{N}(1)$ protonated tautomer via 18ts to give the NO dimer. The barrier for the decomposition of 20, 20ts, could not be determined as attempts to optimize the transition structure led to the products, the NO dimer and amine complex, or the starting structure, 20. This suggests that $\mathbf{2 0}$ lies in a very shallow minimum and has an exceptionally small barrier to decomposition. An upper limit to the barrier of decomposition, 20ts, can be estimated from the $0.9 \mathrm{kcal} / \mathrm{mol}$ barrier for 18ts. Species 18 and 20 have very similar energies, differing by only $0.7 \mathrm{kcal} / \mathrm{mol}$ (Figure 11). The approximate barriers in the gas phase optimizations using the constrained $\mathrm{NN}$ bond, $\mathbf{1 8 f}$ and $\mathbf{2 0 f}$, also possess very similar energetics in aqueous solution, differing by about $3 \mathrm{kcal} / \mathrm{mol}$ (Figure 10). These data indicate that species $\mathbf{2 0}$ and $\mathbf{1 8}$ possess virtually the same energetic profiles and would be expected to decompose with similar rates. Species $\mathbf{2 0}$ and $\mathbf{1 8}$ could thus be used interchangeably in the following discussion. Only $\mathbf{2 0}$ will be considered, as it is slightly lower in energy than $\mathbf{1 8}$, and the ground state protonated species, $\mathbf{1 3}$, is a (Z)-[NONO]ate similar to $\mathbf{2 0}$. 


\section{The $\mathrm{pH}$-dependent mechanism of primary amine NONOate decomposition}

The decomposition of NONOates in both their monobasic (Figure 7) and fully protonated forms (Figure 11) can be thought of in terms of the equilibrium between low-energy tautomers, which are stable, and certain high-energy tautomers that decompose readily. To use the example of $Z \mathrm{MA} / \mathrm{NO}$, decomposition occurs essentially without a barrier from $\mathbf{1 0}$. Of course, at any given time, most of the NONOate will exist as the stable, low-energy tautomer 4 . The rate of decomposition from 4 will depend on the small equilibrium population of $10\left(\mathrm{~K}_{10}=[\mathbf{1 0}] /[\mathbf{4}]\right)$. At lower $\mathrm{pH}$, the monobasic NONOate will also be in equilibrium with its protonated form. This equilibrium is expressed in the $\mathrm{pK}_{\mathrm{a}}$, based on the most stable protonated and non-protonated isomers $\left(\mathrm{K}_{\mathrm{a} 13}=[4]\left[\mathrm{H}^{+}\right] /[13]\right)$. Decomposition of the protonated NONOate is also based on the equilibrium population of a metastable tautomer $\left(\mathrm{K}_{20}=[\mathbf{2 0}] /[\mathbf{1 3}]\right)$. Compiling these pathways and other, non-productive equilibria in both the protonated and non-protonated forms, an overall kinetic model for decomposition is summarized in Figure 12. This model corresponds to the kinetic expression for $k_{\mathrm{obs}}$ in Equation 3 (where $\mathrm{d} / \mathrm{dt}$ [NONOate] $=-k_{\mathrm{obs}}$ [NONOate]). According to the relative energies listed in Figures 7 and $11, \mathrm{~K}_{10}, \mathrm{~K}_{6}, \mathrm{~K}_{20}, \mathrm{~K}_{17}$, etc., are all much less than 1 , and so Equation 3 may be simplified to Equation $4 \mathrm{a}$, which may alternatively be expressed as Equation $4 \mathrm{~b}$ for correspondence with previously published kinetic models for similar NONOate systems. ${ }^{7}$

$k_{\mathrm{obs}}=\left(\mathrm{K}_{10} k_{10}+\mathrm{K}_{20} k_{20}\left(\left[\mathrm{H}^{+}\right] / \mathrm{K}_{\mathrm{a} 13}\right)\right) /\left(\left(1+\mathrm{K}_{10}+\mathrm{K}_{6}+\ldots\right)+\left(1+\mathrm{K}_{20}+\mathrm{K}_{15}+\mathrm{K}_{17}+\ldots\right)\left(\left[\mathrm{H}^{+}\right] / \mathrm{K}_{\mathrm{a} 13}\right)\right)$

$$
k_{\mathrm{obs}}=\left(\mathrm{K}_{10} k_{10}+\mathrm{K}_{20} k_{20}\left(\left[\mathrm{H}^{+}\right] / \mathrm{K}_{\mathrm{a} 13}\right)\right) /\left(1+\left(\left[\mathrm{H}^{+}\right] / \mathrm{K}_{\mathrm{a} 13}\right)\right)
$$

$$
k_{\mathrm{obs}}=\left(\mathrm{K}_{10} k_{10} \mathrm{~K}_{\mathrm{a} 13}+\mathrm{K}_{20} k_{20}\left[\mathrm{H}^{+}\right]\right) /\left(\mathrm{K}_{\mathrm{a} 13}+\left[\mathrm{H}^{+}\right]\right)
$$

Figure 13 shows experimentally determined $\mathrm{pH}$-dependent rate constants $\left(k_{\text {obs }}\right)$ for IPA/NO decomposition. ${ }^{18} \mathrm{~A}$ least-squares fit of Equation $4 \mathrm{a}$ to these data indicates $\mathrm{K}_{10} k_{10}=0.0019$ $\mathrm{s}^{-1}, \mathrm{~K}_{20} k_{20}=0.070 \mathrm{~s}^{-1}$, and $\mathrm{pK}_{\mathrm{a} 13}=4.5$. It is readily apparent that the fit value of $\mathrm{K}_{20} k_{20}$ must reflect something of a lower limit, since unfortunately no data are available below $\mathrm{pH}$ $=3 . \mathrm{K}_{10} k_{10}$ reflects the cumulative barrier from 4 to $\mathbf{1 0 t s}$, which theory predicts to be only slightly higher than 10. Likewise, $\mathrm{K}_{20} k_{20}$ reflects $\Delta G^{\ddagger}(\mathbf{2 0 t s - 1 3})$. Based on the fit values, $\Delta G^{\ddagger}(\mathbf{1 0 t s}-\mathbf{4})=21.2 \mathrm{kcal} / \mathrm{mol}$, compared to a calculated prediction of $14.6 \mathrm{kcal} / \mathrm{mol}$, and $\Delta G^{\ddagger}(\mathbf{2 0 t s}-\mathbf{1 3})=19.0$, compared to a calculated lower-limit $(\Delta G(\mathbf{2 0 - 1 3}))$ of $11.2 \mathrm{kcal} / \mathrm{mol}$.

According to the mechanism in Figure 12, the rate of decomposition in the low $\mathrm{pH}$ range, to form $\mathrm{NO}$, will become constant once diprotonation exceeds the tautomerization of the monobasic isomers. This presumably occurs at a $\mathrm{pH}$ for which kinetic measurements have not yet been attempted. The $\mathrm{pH}$ range of 5 to 6 is an interesting region of the curve where the production of both $\mathrm{NO}$ and $\mathrm{HNO}$ is significant. The fit as we have implemented it applies equally well to either the $Z$ NONOates, as we have used to explain it, or the $E$ NONOates $(3,9,12$, and 18 in place of $4,10,13$, and 20), or even a combination of the two if they are in fast equilibrium. The fit might be improved in the inflection region if both $Z$ and $E$ NONOates are present and they react separately ( 3 does not equilibrate with $\mathbf{4})$ but in parallel with each other. A difference in $\mathrm{pK}_{\mathrm{a}}$ of 1 unit, as is predicted by our calculations, could extend the mid-pH inflection region of the curve horizontally to fit the data better. Unfortunately, this possibility must remain purely speculative, since it introduces too many variables into the system to make any kind of meaningful fit to the available experimental 
data. There could also be general-acid catalyzed decomposition pathways occurring that have not been investigated; such processes would depend upon the nature and concentration of the acid.

\section{Summary}

IPA/NO has been shown experimentally to produce both $\mathrm{HNO}$ and $\mathrm{NO}$ in a $\mathrm{pH}$ dependent process. ${ }^{18}$ This decomposition was studied theoretically using MA/NO as a simplified model for IPA/NO. This investigation provides a possible mechanism for the production of $\mathrm{HNO}$ and $\mathrm{NO}$ from the decomposition of monoalkylamine NONOates. At high $\mathrm{pH}$, the $(Z)-$ monoanion protonated at $\mathrm{N}(1)$ is predicted to be the most stable isomer. Tautomerization to the higher energy isomer protonated at $\mathrm{N}(3)$ will be slow and independent of $\mathrm{pH}$. This tautomer will be a very minor component of the equilibrium, but once formed will spontaneously and rapidly dissociate to produce $\mathrm{HNO}$ and the deprotonated nitrosamine due to the very small barrier to $\mathrm{NN}$ bond cleavage. The resulting nitrosamine is expected to be unstable and rapidly decompose to the primary alcohol and $\mathrm{N}_{2} \cdot{ }^{30}$

As the $\mathrm{pH}$ is lowered, the $(Z)$-monoanion protonated at $\mathrm{N}(1)$ is predicted to be protonated at $\mathrm{O}(2)$. Tautomerization to an isomer diprotonated at $\mathrm{N}(1)$ gives a species which has a very low barrier to NN bond cleavage. Breaking of the $\mathrm{NN}$ bond of this isomer results in cleavage of the amine/NO adduct back to the starting materials, neutral amine and two molecules of NO. The theoretical $\mathrm{pK}_{13}, 4$, is close to the experimental $\mathrm{pK}_{\mathrm{a}}$ of $4.5 .{ }^{18}$ The calculated rate constants and $\mathrm{pK}_{\mathrm{a}}$ are consistent with the observed competition (Figure 13) between formation of $\mathrm{HNO}$, through a tautomer protonated at $\mathrm{N}(3)$ and of $\mathrm{NO}$, also through a tautomer but doubly protonated at N(1) (Figure 12).

This theoretical study has suggested a mechanism for the $\mathrm{pH}$-dependent decomposition of monoalkylamine NONOates, such as IPA/NO. The results should be of value for the design of other $\mathrm{HNO}$ and $\mathrm{NO}$ donors.

\section{Supplementary Material}

Refer to Web version on PubMed Central for supplementary material.

\section{Acknowledgments}

We are grateful to the National Institute of General Medical Sciences, National Institutes of Health (K.N.H.) and the National Science Foundation (J.M.F.) for financial support of this research. A.S.D. acknowledges the support of the National Institutes of Health, Chemistry and Biology Interface Training Grant from UCLA.

\section{References}

1. Reilly, EL. German Patent. 1085 166. July 14. 1960

2. (a) Drago RS, Paulik FE. J Am Chem Soc. 1960; 82:96.(b) Drago RS, Karstetter BR. J Am Chem Soc. 1961; 83:1819.(c) Longhi R, Ragsdale RO, Drago RS. Inorg Chem. 1962; 1:768.(d) Ragsdale RO, Karstetter BR, Drago RS. Inorg Chem. 1965; 4:420.

3. (a) Keefer LK. CHEMTECH. 1998; 28:30.(b) Saavedra J, Keefer L. Chem Ber. 2000; 36:30.(c) Keefer LK. Annu Rev Pharmacol Toxicol. 2003; 43:585. [PubMed: 12415121] (d) Thomas DD, Miranda KM, Espey MG, Citrin D, Jourd'heuil D, Paolocci N, Hewett SJ, Colton CA, Grisham MB, Feelisch M, Wink DA. Meth Enz. 2002; 359:84.

4. Ignarro, LJ. Nitric Oxide Biology and Pathobiology. Academic Press; San Diego, CA: 2000.

5. (a) Davies KM, Wink DA, Saavedra JE, Keefer LK. J Am Chem Soc. 2001; 123:5473. [PubMed: 11389629] (b) Pavlos CM, Xu H, Toscano JP. Free Rad Biol Med. 2004; 37:745. [PubMed: $15304250]$ 
6. (a) Taylor DK, Bytheway I, Barton DHR, Bayse CA, Hall MB. J Org Chem. 1995; 60:435.(b) Pavlos CM, Cohen AD, D’Sa RA, Sunoj RB, Wasylenko WA, Kapur P, Relyea HA, Kumar NA, Hadad CM, Toscano JP. J Am Chem Soc. 2003; 125:14934. [PubMed: 14640671]

7. Dutton AS, Fukuto JM, Houk KN. Inorg Chem. 2004; 43:1039. and references therein. [PubMed: 14753826]

8. Shafirovich V, Lymar SV. Proc Natl Acad Sci U S A. 2002; 99:7340. [PubMed: 12032284]

9. Liochev SI, Fridovich I. Free Radical Biol Med. 2003; 34:1399. [PubMed: 12757850]

10. Miranda KM, Paolocci N, Katori T, Douglas DT, Ford E, Bartberger M, Espey MG, Kass DA, Feelisch M, Fukuto JM, Wink DA. Proc Natl Acad Sci U S A. 2003; 100:9196. [PubMed: 12865500]

11. Dutton AS, Fukuto JM, Houk KN. J Am Chem Soc. 2004; 126:3795. [PubMed: 15038733]

12. (a) Shafirovich V, Lymar SV. Proc Natl Acad Sci U S A. 2002; 99:7340. [PubMed: 12032284] (b) Bartberger MD, Liu W, Ford E, Miranda KM, Switzer C, Fukuto JM, Farmer PJ, Wink DA, Houk KN. Proc Natl Acad Sci U S A. 2002; 99:10958. [PubMed: 12177417]

13. Shafirovich V, Lymar SV. J Am Chem Soc. 2003; 125:6547. [PubMed: 12785794]

14. Miranda KM, Paolocci N, Katori T, Thomas DD, Ford E, Bartberger MD, Espey MG, Kass DA, Feelisch M, Fukuto JM, Wink DA. Proc Natl Acad Sci U S A. 2003; 100:9196. [PubMed: 12865500] and references therein

15. (a) Angeli A. Gazz Chim Ital. 1896; 26:17.(b) Bonner FT, Ravid B. Inorg Chem. 1975; 14:558.(c) Hughes MN, Wimbledon PE. J Chem Soc Dalton Trans. 1976:703.

16. Cosby K, Partovi KS, Crawford JH, Patel R, Reiter CD, Martyr S, Yang BK, Waclawiw MA, Salow G, Xu X, Huang KT, Shields H, Kim-Shapiro DB, Schechter AN, Cannon RO, Gladwin MT. Nat Med. 2003; 9:1498. [PubMed: 14595407]

17. (a) Maragos CM, Morley D, Wink DA, Dunams TM, Saavedra JE, Hoffman A, Bove AA, Isaac L, Hrabie JA, Keefer LK. J Med Chem. 1991; 34:3242. [PubMed: 1956043] (b) Hrabie JA, Klose JR, Wink DA, Keefer LK. J Org Chem. 1993; 58:1472.

18. (a) Miranda KM, et al. Manuscript in preparation. For detailed description of the experimental method of $\mathrm{pH}$ dependent decomposition: (b) Miranda KM, Dutton AS, Ridnour LA, Foreman CA, Ford E, Paolocci N, Katori T, Tocchetti CG, Mancardi D, Thomas DD, Espey MG, Houk KN, Fukuto JM, Wink DA. J Am Chem Soc. 2005; 127:722. [PubMed: 15643898]

19. (a) Lee C, Yang W, Parr RG. Phys Rev B. 1988; 37:785.(b) Becke AD. J Chem Phys. 1993; 98:5648.

20. Frisch, MJ., et al. Gaussian 98 (Revision A.1). Gaussian, Inc; Pittsburgh PA: 1998.

21. Cossi M, Barone R, Cammi R, Tomasi J. Chem Phys Lett. 1996; 255:327.

22. Cossi M, Rega N, Scalmani G, Barone V. J Comp Chem. 2003; 24:669. [PubMed: 12666158]

23. Takano Y, Houk KN. J Chem Theory Comp. 2005; 1:70.

24. Montgomery JA, Ochterski JW, Peterson GA. J Chem Phys. 1994; 101:5900.

25. Frisch, MJ., et al. Gaussian 03 (Revision B.04). Gaussian, Inc; Pittsburgh PA: 2003.

26. Pliego JR Jr, Riveros JM. J Phys Chem A. 2002; 106:7434.

27. Hope H, Sequeira MR. Inorg Chem. 1973; 12:286.

28. (a) Sayós R, Valero R, Anglada JM, González M. J Chem Phys. 2000; 112:6608.(b) Zhao YL, Bartberger MD, Goto K, Shimada K, Kawashima T, Houk KN. J Am Chem Soc. 2005; 127:7964. [PubMed: 15926791]

29. Shafirovich V, Lymar SV. Proc Natl Acad Sci U S A. 2002; 99:7340-7345. [PubMed: 12032284]

30. Wink DA, Kasprazak KS, Maragos CM, Elespuru RK, Misra M, Dunams TM, Cebula TA, Koch WH, Andrews AW, Allen JS, Keefer LK. Science. 1991; 254:1001. [PubMed: 1948068] 


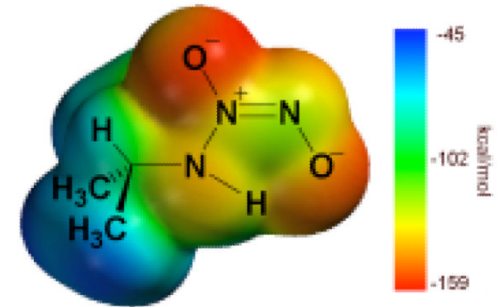

a.

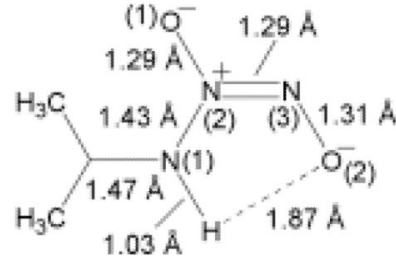

b.

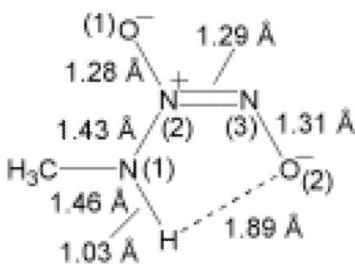

c.

Figure 1.

(a) The computed electrostatic potential of IPA/NO projected onto an electronic isodensity surface. The scale shows the difference in electrostatic potential, with red representing areas of large negative charge densities. The B3LYP/6-311+G(d) optimized geometry of (b) IPA/ $\mathrm{NO}$, and (c) the model compound, MA/NO, with distances given in $\AA$. The numbers in parenthesis represent the atom numbering scheme used throughout the paper. 


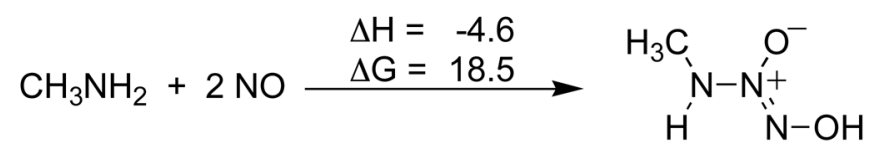

$$
\mathrm{H}_{\mathrm{H}^{\prime}}^{\mathrm{N}-\mathrm{N}^{\prime} \mathrm{O}^{\prime}}
$$

E
$\underset{\mathrm{H}}{\mathrm{H}^{\prime}} \stackrel{\mathrm{O}^{-}}{\mathrm{H}_{3}^{\prime}} \mathrm{N}^{\mathrm{C}}-\mathrm{O}^{-}$

Figure 2.

Computed energetics for the formation of MA/NO, and comparison of $\mathrm{E}$ and $\mathrm{Z}$ configurations in the anionic form. Relative enthalpies and free energies are given in kcal/ mol for the gas phase as computed with B3LYP/6-311+G(d). 
<smiles>C[N-]/[N+]([O-])=N/[O-]</smiles>

1

$$
\Delta \mathrm{H}_{\mathrm{rel}}=0.3
$$

$\Delta G_{\text {rel }}=0.1$

$\Delta \mathrm{G}_{\mathrm{aq}, \mathrm{PCM}}=0.0$

$\Delta G_{\text {aq, }}$ CPCM $=0.0$<smiles>CN[N+]([O-])=N[O-]</smiles>

$1 a$<smiles>CN[N+]([O-])=N[O-]</smiles>

2<smiles>C[N-]/[N+]([O-])=N\[O-]</smiles>

$2 a$

Figure 3.

Relative energetics for the isomers of deprotonated MA/NO. Relative enthalpies and free energies are give in $\mathrm{kcal} / \mathrm{mol}$ for the gas phase and in aqueous solvation using both the PCM and CPCM models (B3LYP/6-311+G(d), PCM (B3LYP/6-311+G(d)), CPCM (HF/ $6-31+G(d))$. 


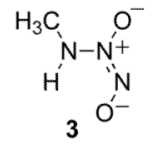

$\Delta \mathrm{H}_{\text {rel }}=0.0$

$\Delta G_{\text {rel }}=0.0$

$\Delta \mathrm{G}_{\mathrm{aq}}, \mathrm{PCM}=0.0$

$\Delta G_{a q, ~} \mathrm{CPCM}=3.1$

$\mathrm{H}_{\mathrm{N}=\mathrm{N}^{\prime} \mathrm{O}^{\prime}-\mathrm{O}^{\prime}}^{\mathrm{O}^{-}} \mathrm{H}$

6

$\Delta \mathrm{H}_{\mathrm{rel}}=5.8$

$\Delta G_{\text {rel }}=5.6$

$\Delta \mathrm{G}_{\mathrm{aq}, \mathrm{PCM}}=1.2$

$\Delta G_{a q}, \mathrm{CPCM}=9.8$

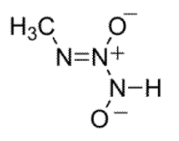

\section{9}

$\Delta \mathrm{H}_{\text {rel }}=14.4$

$\Delta G_{\text {rel }}=14.4$

$\Delta G_{a q}, P C M=5.7$

$\Delta \mathrm{G}_{\mathrm{aq}, \mathrm{CPCM}}=9.7$

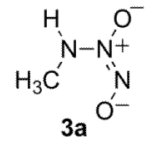

$\Delta \mathrm{H}_{\text {rel }}=5.8$

$\Delta \mathrm{G}_{\mathrm{rel}}=5.8$

$\Delta G_{a q, P C M}=6.5$

$\Delta G_{a q, ~}$ CPCM $=5.9$

$\mathrm{H}_{3} \mathrm{C}^{\mathrm{N}=\mathrm{N}^{\prime+}} \stackrel{\mathrm{O}-\mathrm{O}^{-}}{\mathrm{H}}$

$6 a$

$\Delta \mathrm{H}_{\mathrm{rel}}=4.0$

$\Delta \mathrm{G}_{\mathrm{rel}}=4.5$

$\Delta \mathrm{G}_{\mathrm{aq}, \mathrm{PCM}}=1.7$

$\Delta \mathrm{G}_{\mathrm{aq}, \mathrm{CPCM}}=11.2$

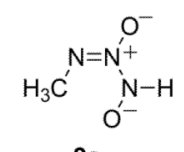

$9 a$

$\Delta \mathrm{H}_{\mathrm{rel}}=17.4$

$\Delta G_{\text {rel }}=17.4$

$\Delta \mathrm{G}_{\mathrm{aq}, \mathrm{PCM}}=16.4$

$\Delta G_{\mathrm{aq}}, \mathrm{CPCM}=19.2$<smiles>CN/[N+]([O-])=N/[O-]</smiles>

$\mathrm{H} \mathrm{N}-\mathrm{O}^{-}$

4

$\Delta \mathrm{H}_{\mathrm{rel}}=4.7$

$\Delta \mathrm{G}_{\mathrm{rel}}=4.4$

$\Delta G_{a q, ~}$ CPCM $=0.0$

$$
\begin{gathered}
\mathrm{N}-\mathrm{N}^{+} \\
\text {"N } \\
\mathrm{O}^{-}
\end{gathered}
$$

7

$\Delta \mathrm{H}_{\mathrm{rel}}=23.6$

$\Delta \mathrm{G}_{\mathrm{rel}}=21.4$

$\Delta G_{a q, P C M}=16.6$

$\Delta G_{a q, ~}$ CPCM $=26.1$
$\Delta G_{\text {aq, }} \mathrm{PCM}=3.1$

$\mathrm{H}_{3} \mathrm{C}_{1} \mathrm{O}-\mathrm{H}$

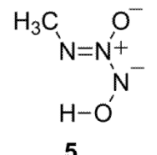

5

$\Delta \mathrm{H}_{\mathrm{rel}}=3.8$

$\Delta \mathrm{G}_{\mathrm{rel}}=3.8$

$\Delta \mathrm{G}_{\mathrm{aq}, \mathrm{PCM}}=3.0$

$\Delta G_{a q}, \mathrm{CPCM}=8.7$

$\Delta \mathrm{G}_{\mathrm{aq}, \mathrm{PCM}}=3.4$

$\Delta G_{\text {aq, }} \mathrm{CPCM}=0.1$

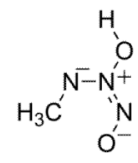

$7 a$

$\Delta \mathrm{H}_{\text {rel }}=25.0$

$\Delta G_{\text {rel }}=24.5$

$\Delta G_{\mathrm{aq}, \mathrm{PCM}}=20.8$

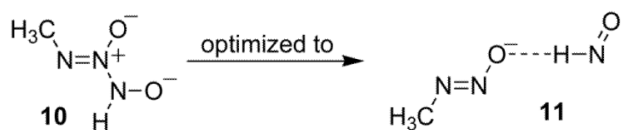

$\mathrm{O}^{-}$optimized to

$\mathrm{H}_{3} \mathrm{C}_{\mathrm{H}^{\prime}}^{\mathrm{N}=\mathrm{N}^{\prime}} \stackrel{-}{\mathrm{N}-\mathrm{O}^{-}}$

$10 \mathrm{a}$
$\mathrm{H}_{3} \mathrm{C}^{\mathrm{N}-\mathrm{N}_{\mathrm{N}}^{\mathrm{O}-\mathrm{H}}} \stackrel{\mathrm{N}-\mathrm{O}^{-}}{\mathrm{O}}$

8

$\Delta \mathrm{H}_{\mathrm{rel}}=12.9$

$\Delta \mathrm{G}_{\text {rel }}=13.3$

$\Delta \mathrm{G}_{\mathrm{aq}}, \mathrm{PCM}=10.9$

$\mathrm{H}_{3} \mathrm{C}$

$\Delta \mathrm{H}_{\text {rel }}=5.9$

$\Delta \mathrm{G}_{\mathrm{rel}}=1.0$

$\Delta \mathrm{G}_{\mathrm{aq}, \mathrm{PCM}}=4.7$

$\Delta \mathrm{G}_{\mathrm{aq}, \mathrm{CPCM}}=10.2$

Figure 4.

Relative energetics for the tautomers of protonated MA/NO. Relative enthalpies and free energies are give in $\mathrm{kcal} / \mathrm{mol}$ for the gas phase and in aqueous solvation using both the PCM and CPCM models (B3LYP/6-311+G(d), PCM (B3LYP/6-311+G(d)), CPCM (HF/

$6-31+G(d))$. 
<smiles>CN([O-])/[N+]([O-])=N/[O-]</smiles>

$\Delta \mathrm{H}_{\text {rel }}=0.0$

$\Delta \mathrm{G}_{\mathrm{rel}}=0.0$

$\Delta \mathrm{G}_{\mathrm{aq}, \mathrm{PCM}}=1.5$

$\Delta \mathrm{G}_{\mathrm{aq}, \mathrm{CPCM}}=1.7$<smiles>CN=[N+]([O-])N[O-]</smiles>

$\Delta \mathrm{H}_{\mathrm{rel}}=18.4$

$\Delta \mathrm{G}_{\text {rel }}=18.3$

$\Delta \mathrm{G}_{\mathrm{aq}, \mathrm{PCM}}=11.1$

$\Delta \mathrm{G}_{\mathrm{aq}, \mathrm{CPCM}}=12.2$<smiles>CN/[N+]([O-])=N/[O-]</smiles>

4

$\Delta \mathrm{H}_{\mathrm{rel}}=6.1$

$\Delta \mathrm{G}_{\mathrm{rel}}=5.8$

$\Delta \mathrm{G}_{\mathrm{aq}, \mathrm{PCM}}=6.0$

$\Delta \mathrm{G}_{\mathrm{aq}, \mathrm{CPCM}}=0.0$

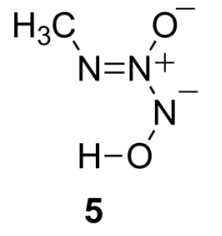

$\Delta \mathrm{H}_{\text {rel }}=0.9$

$\Delta \mathrm{G}_{\text {rel }}=1.0$

$\Delta \mathrm{G}_{\mathrm{aq}, \mathrm{PCM}}=1.7$

$\Delta \mathrm{G}_{\mathrm{aq}, \mathrm{CPCM}}=4.5$<smiles>CN=[N+]([O-])NO</smiles>

6

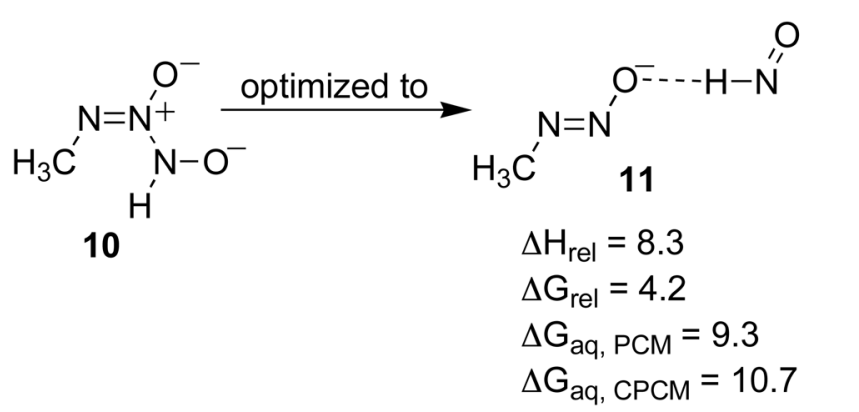

Figure 5.

Relative energetics for the tautomers of protonated MA/NO. Relative enthalpies and free energies are given in $\mathrm{kcal} / \mathrm{mol}$ for the gas phase and in aqueous solvation using both the PCM and CPCM models (CBS-QB3, PCM (B3LYP/6-311+G(d)), CPCM (HF/6-31+G(d)). 
<smiles>[Y6]N=[N+]([O-])NC</smiles>

3

$\Delta \mathrm{H}_{\mathrm{rel}}=0.0$

$\Delta \mathrm{G}_{\mathrm{rel}}=0.0$

$\Delta G_{\mathrm{aq}, \mathrm{PCM}}=0.0$

$\Delta \mathrm{G}_{\mathrm{aq}, \mathrm{CPCM}}=0.0$

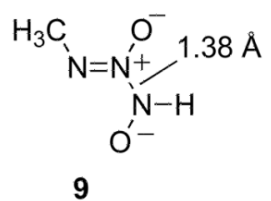

$\Delta \mathrm{H}_{\text {rel }}=14.4$

$\Delta \mathrm{G}_{\mathrm{rel}}=14.4$

$\Delta \mathrm{G}_{\mathrm{aq}, \mathrm{PCM}}=5.7$

$\Delta \mathrm{G}_{\mathrm{aq}, \mathrm{CPCM}}=6.6$

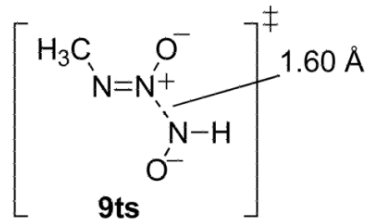

$\Delta \mathrm{H}_{\text {rel }}=15.0$

$\Delta \mathrm{G}_{\mathrm{rel}}=14.9$

$\Delta \mathrm{G}_{\mathrm{aq}, \mathrm{PCM}}=7.6$

$\Delta \mathrm{G}_{\mathrm{aq}, \mathrm{CPCM}}=8.3$

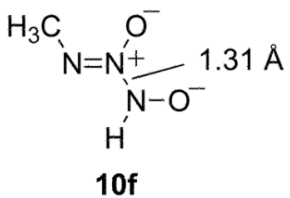

$\Delta \mathrm{H}_{\text {rel }}=23.1$

$\Delta \mathrm{G}_{\mathrm{rel}}=23.3$

$\Delta \mathrm{G}_{\mathrm{aq}, \mathrm{PCM}}=14.6$

$\Delta \mathrm{G}_{\mathrm{aq}, \mathrm{CPCM}}=13.7$

Figure 6.

Relative energetics for the transition state structure of 9,9 ts, structure 9 and the constrained structure of 10, structure 10f, relative to species $\mathbf{3}$. Relative enthalpies and free energies are give in $\mathrm{kcal} / \mathrm{mol}$ for the gas phase and in aqueous solvation using both the PCM and CPCM models (B3LYP/6-311+G(d), PCM (B3LYP/6-311+G(d)), CPCM (HF/6-31+G(d)). 


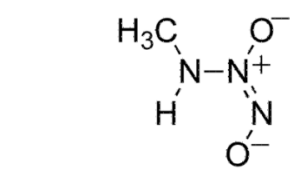

3

$\Delta \mathrm{H}_{\mathrm{aq}, \text { rel }}=1.0$

$\Delta \mathrm{G}_{\mathrm{aq}, \text { rel }}=1.2$

$\mathrm{pK}_{\mathrm{a}, \mathrm{rel}}=28$

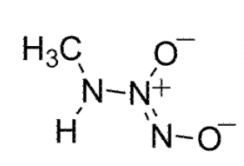

4

0.0

0.0

29<smiles>CN=[N+]([O-])NO</smiles>

6

9.7

10.3

21<smiles>CN=[N+]([O-])N[O-]</smiles>

9

12.3

12.5

19

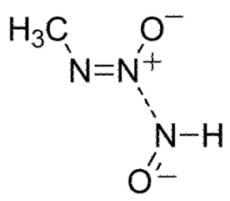

9ts

$\Delta \mathrm{H}_{\mathrm{aq}, \mathrm{rel}}=14.7$ $\Delta \mathrm{G}_{\mathrm{aq} \text {, rel }}=13.9$ $\mathrm{pK}_{\mathrm{a} \text {, rel }}=18$<smiles>CN=[N+]([O-])N[O-]</smiles>

10

13.9

13.9

18

\section{Figure 7.}

Relative energetics for species optimized in the PCM aqueous solvation model. Relative enthalpies and free energies are given in $\mathrm{kcal} / \mathrm{mol}$. (PCM (B3LYP/6-311+G(d))). 


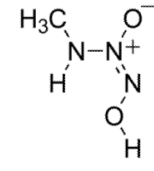

12

\begin{abstract}
$\Delta \mathrm{H}_{\mathrm{rel}}=4.3$
\end{abstract}
$\Delta \mathrm{G}_{\mathrm{rel}}=4.1$

$\Delta G_{\text {aq, } P C M}=0.8 \quad \Delta G_{\text {aq, } P C M}=0.0$

$\Delta \mathrm{G}_{\mathrm{aq}, \mathrm{CPCM}}=1.1 \Delta \mathrm{G}_{\mathrm{aq}, \mathrm{CPCM}}=0.0$

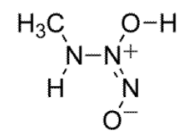

14
H

15

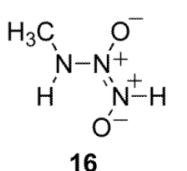

16

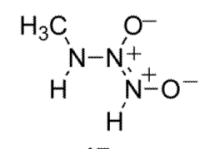

17

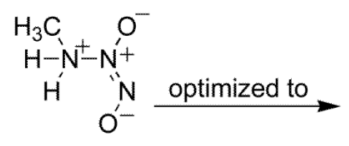

18

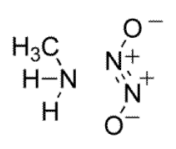

19

$\Delta \mathrm{H}_{\text {rel }}=14.0$

$\Delta \mathrm{G}_{\mathrm{rel}}=10.3$

$\Delta \mathrm{G}_{\mathrm{aq}, \mathrm{PCM}}=12.7$

$\Delta \mathrm{G}_{\mathrm{aq}, \mathrm{CPCM}}=15.9$

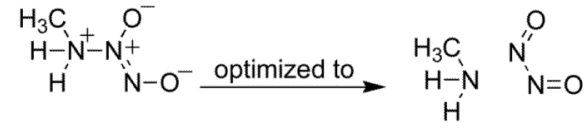

20

$\Delta \mathrm{H}_{\text {rel }}=11.0 \quad \Delta \mathrm{H}_{\text {rel }}=15.4$

$\Delta \mathrm{G}_{\mathrm{rel}}=10.9 \quad \Delta \mathrm{G}_{\mathrm{rel}}=15.2$

$\Delta \mathrm{G}_{\mathrm{rel}}=5.1 \quad \Delta \mathrm{G}_{\mathrm{rel}}=10.9$

$\Delta \mathrm{G}_{\mathrm{aq}, \mathrm{PCM}}=4.8$

$\Delta G_{a q}, P C M=8.8$

Figure 8.

Relative enthalpies and free energies for the gas phase in $\mathrm{kcal} / \mathrm{mol}$ for the diprotonated species and in aqueous solvation using both the PCM and CPCM models (B3LYP/ 6-311+G(d), PCM (B3LYP/6-311+G(d)), CPCM (HF/6-31+G(d)). 


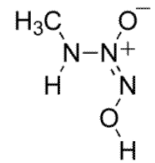

12

\begin{abstract}
$\Delta \mathrm{H}_{\text {rel }}=6.6$
\end{abstract}
$\Delta \mathrm{G}_{\mathrm{rel}}=6.4$

$\Delta G_{\text {aq, } P C M}=3.1 \quad \Delta G_{\text {aq, } P C M}=0.0$

$\Delta \mathrm{G}_{\mathrm{aq}, \mathrm{CPCM}}=3.4 \Delta \mathrm{G}_{\mathrm{aq}, \mathrm{CPCM}}=0.0$

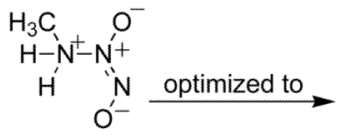

18

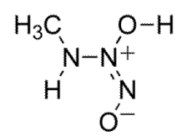

14

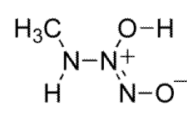

15

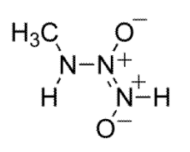

16

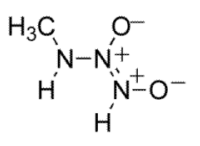

17

$$
\Delta \mathrm{H}_{\text {rel }}=12.1 \quad \Delta \mathrm{H}_{\text {rel }}=8.1 \quad \Delta \mathrm{H}_{\text {rel }}=16.9 \quad \Delta \mathrm{H}_{\text {rel }}=20.8
$$

$\Delta \mathrm{G}_{\mathrm{rel}}=11.4$

$\Delta \mathrm{G}_{\text {rel }}=7.2$

$\Delta \mathrm{G}_{\mathrm{rel}}=16.9$

$\Delta G_{\text {rel }}=20.6$

$\Delta G_{a q, P C M}=11.6 \quad \Delta G_{a q, P C M}=7.6 \quad \Delta G_{a q, P C M}=10.8 \quad \Delta G_{a q, P C M}=14.2$

$\Delta \mathrm{G}_{\mathrm{aq}, \mathrm{CPCM}}=12.5$

$\Delta \mathrm{G}_{\mathrm{aq}, \mathrm{CPCM}}=7.9 \Delta \mathrm{G}_{\mathrm{aq}, \mathrm{CPCM}}=9.7$

$\Delta \mathrm{G}_{\mathrm{aq}, \mathrm{CPCM}}=6.8$

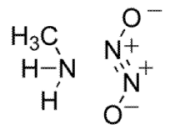

19

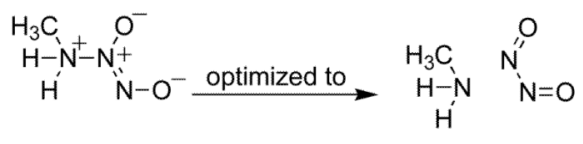

20

21

$\Delta \mathrm{H}_{\mathrm{rel}}=8.9$

$\Delta \mathrm{G}_{\text {rel }}=4.5$

$\Delta \mathrm{G}_{\mathrm{aq}, \mathrm{PCM}}=11.0$

$\Delta \mathrm{G}_{\mathrm{aq}, \mathrm{CPCM}}=14.6$

Figure 9.

Relative enthalpies and free energies for the gas phase in $\mathrm{kcal} / \mathrm{mol}$ for the diprotonated species and in aqueous solvation using both the PCM and CPCM models (CBS-QB3, PCM (B3LYP/6-311+G(d)), CPCM (HF/6-31+G(d)). 


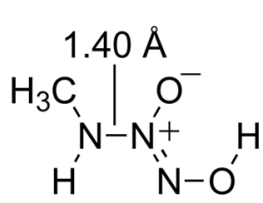

13

$\Delta \mathrm{H}_{\text {rel }}=0.0$

$\Delta \mathrm{G}_{\mathrm{rel}}=0.0$

$\Delta \mathrm{G}_{\mathrm{aq}, \mathrm{PCM}}=0.0$

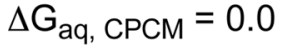

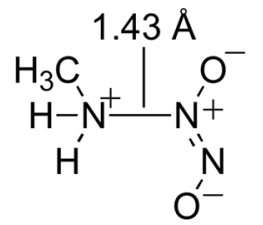

$18 f$

$\Delta \mathrm{H}_{\text {rel }}=24.5$

$\Delta \mathrm{G}_{\mathrm{rel}}=24.5$

$\Delta \mathrm{G}_{\mathrm{aq}, \mathrm{PCM}}=13.6$

$\Delta \mathrm{G}_{\mathrm{aq}, \mathrm{CPCM}}=11.9$

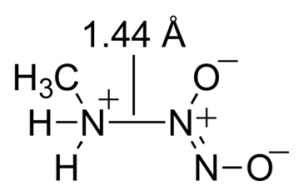

$20 f$

$\Delta \mathrm{H}_{\text {rel }}=31.3$

$\Delta \mathrm{G}_{\mathrm{rel}}=30.8$

$\Delta \mathrm{G}_{\mathrm{aq}, \mathrm{PCM}}=16.7$

$\Delta \mathrm{G}_{\mathrm{aq}, \mathrm{CPCM}}=10.1$

\section{Figure 10.}

Relative energetics for the constrained structures of 18 and 20 , structures $18 f$ and $20 f$ respectively, relative to species 13. Relative enthalpies and free energies are give in $\mathrm{kcal} / \mathrm{mol}$ for the gas phase and in aqueous solvation using both the PCM and CPCM models (B3LYP/ 6-311+G(d), PCM (B3LYP/6-311+G(d)), CPCM (HF/6-31+G(d)). 


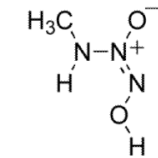

12

$\Delta \mathrm{H}_{\text {aq, rel }}=0.1$

$\Delta \mathrm{G}_{\text {aq, rel }}=0.3$

$\mathrm{pK}_{\mathrm{a}, \text { rel }}=4$

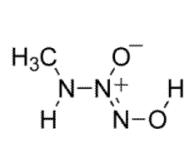
$\mathrm{H}_{3} \mathrm{C}_{1} \quad \mathrm{O}^{-}$

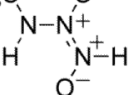

16

6.9

7.1

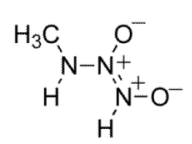

17

7.3

6.7

0

$$
\underset{\mathrm{O}^{\prime-}}{\mathrm{H}-\mathrm{N}^{\mathrm{N}}-\mathrm{N}^{\mathrm{O}}+}
$$

18

12.4

11.9

$-4$
$\underset{\mathrm{H}^{-}}{\mathrm{H}^{\mathrm{H}_{3}}} \stackrel{\mathrm{O}^{-}}{\mathrm{O}^{-}}$

20

11.5

11.2
-4

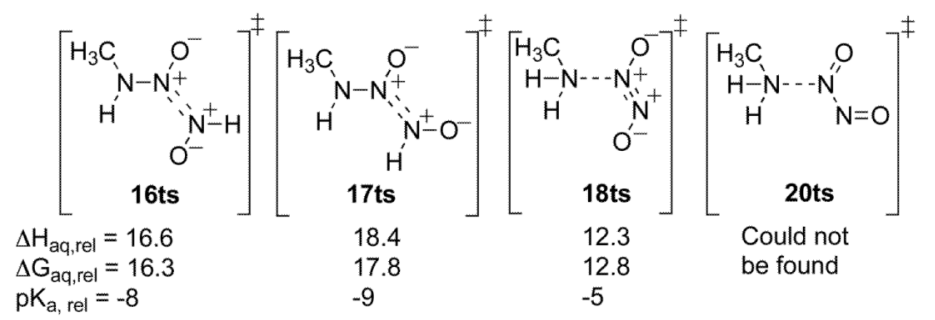

Figure 11.

Relative energetics for species optimized in the PCM aqueous solvation model. Relative enthalpies and free energies are given in $\mathrm{kcal} / \mathrm{mol}$. (PCM (B3LYP/6-311+G(d))). 

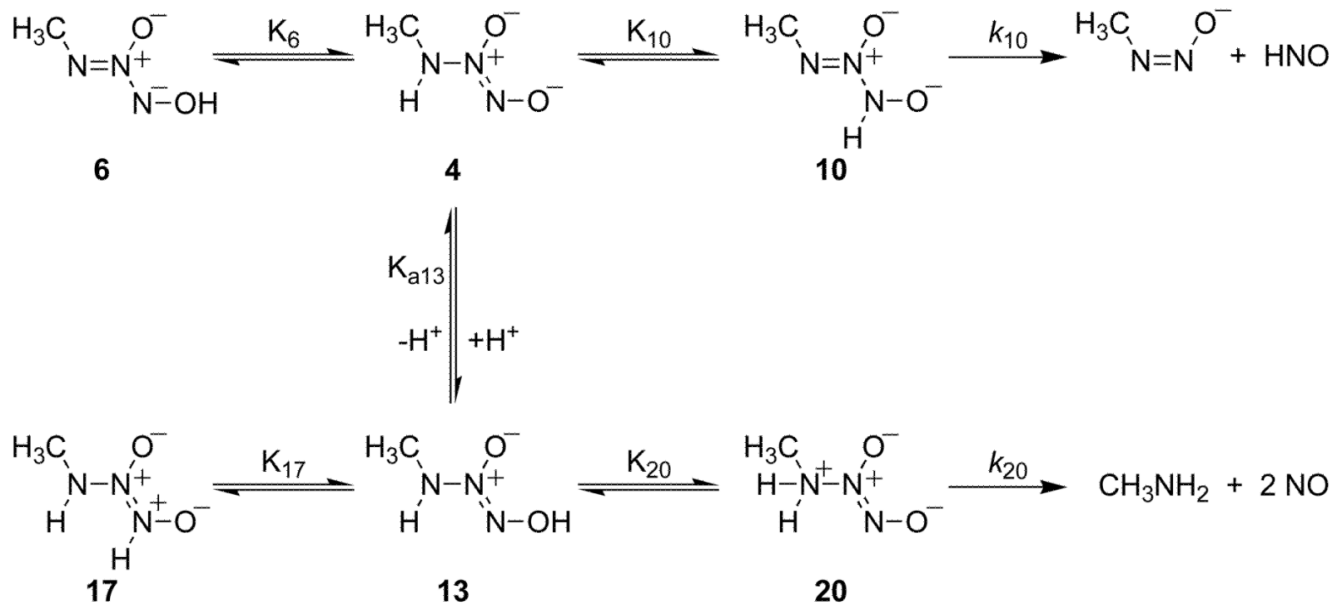

Figure 12.

Theoretical mechanism for the $\mathrm{pH}$-dependent production of HNO and NO from MA/NO. 


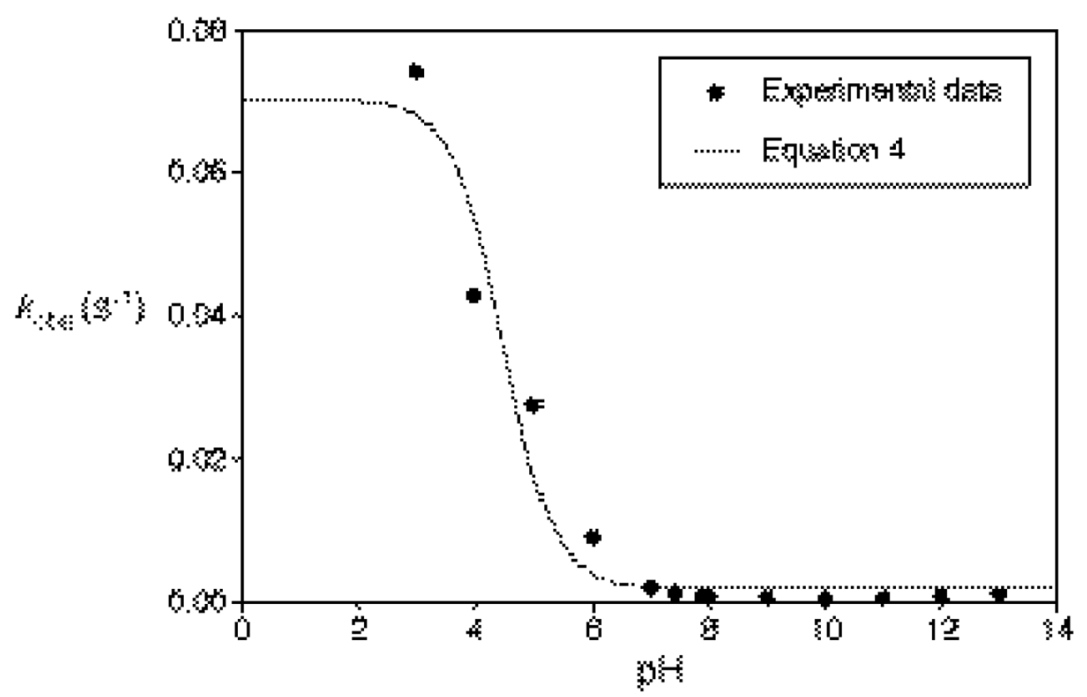

Figure 13.

Plot of experimentally observed rate constants versus $\mathrm{pH}$ for decomposition of the sodium salt of IPA/NO, along with least-squares fit to Equation 4: $\mathrm{K}_{10} k_{10}=0.0019, \mathrm{~K}_{20} k_{20}=0.070$, $\mathrm{pK}_{\mathrm{a} 13}=4.5\left(R^{2}=0.95\right)$. 